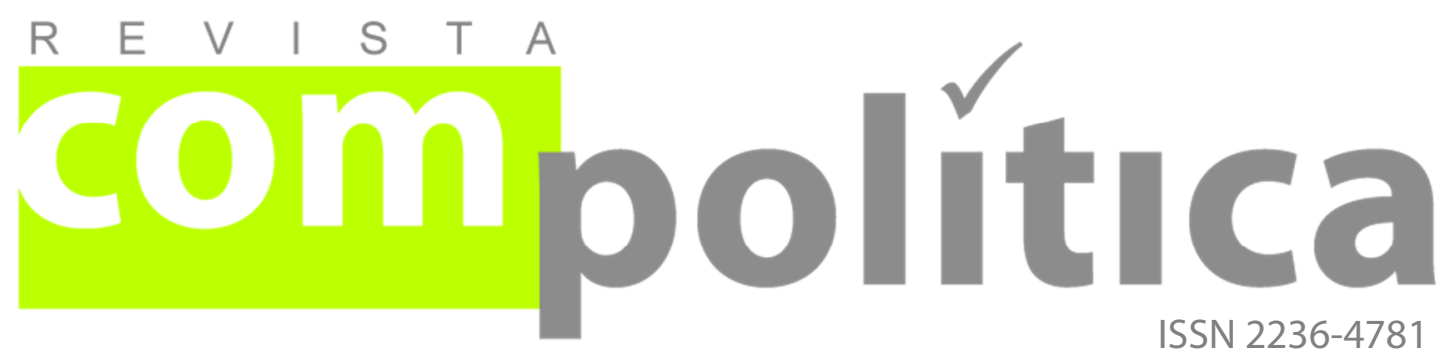

[entrevista com Vinicius WU]

Svab, Haydée

Engenheira civil com dupla formação em arquitetura pela USP, especialista em Democracia Participativa, Repúblicas e Movimentos Sociais pela UFMG. Atualmente, trabalha no Metrô-SP e é mestranda em Engenharia de Transportes na Poli-USP. É membro da comunidade Transparência Hacker e foi co-fundadora do PoliGNU Grupo de Estudos de Software Livre da Poli-USP.

* Esta entrevista foi realizada em 02 de julho de 2014, como parte da pesquisa para a monografia "Espaço Digital, Participação Real", de autoria de Haydée Svab, orientação de Leonardo Avritzer e coorientação de Rayza Sarmento, ambos parte do corpo docente do curso de Especialização "Democracia Participativa, República e Movimentos Sociais" da UFMG/FAFICH/PRODEP.

Gabinete Digital: uma experimentação que mistura política com novas tecnologias de informação comunicação 


\section{Gabinete Digital: uma experimentação que mistura política com novas tecnologias de informação e comunicação}

\section{[Gabinete Digital (Digital Cabinet): an experiment that mixes political with new information and communication technologies]}

SVAB, Haydée

[entrevista com Vinicius WU]

$\mathrm{D}$

iversos teóricos afirmam que a representação política está passando por uma crise atualmente e há quem aponte como perspectiva possível para a superação dessa crise a criação e/ou aprimoramento de mecanismos participativos (AVRITZER, 2012). Assim, é cada vez mais frequente a identificação e a vinculação entre o caráter democrático das governos e a participação social, categoria empregada a partir da década de 1980. Pateman (1992, p.58) já alertava que "será somente praticando o governo popular em pequena escala que o povo terá alguma possibilidade de aprender a exercitá-lo em maior escala" e, corroborando com esse raciocínio, iniciativas de democracia digital vêm surgindo e tornando palpável essa experimentação democrática. Internacionalmente ficaram conhecidas iniciativas como a Cidade Digital holandesa na década de 1990 e a consulta popular islandesa sobre alterações constitucionais em 2012. No Brasil,existem algumas iniciativas entre as quais o Gabinete Digital, no âmbito do governo estadual gaúcho. Não por acaso, uma das iniciativas brasileiras mais robustas de participação cidadã por meio digital nasce no Rio Grande do Sul - este estado também foi um pioneiro nacional na implementação de mecanismos 
de participação presencial abrigando as primeiras iniciativas de orçamento participativo (em Porto Alegre).

Participar per si não é uma atividade necessariamente ligada ao Estado ou alguma instância oficial de governo, entretanto, boa parte das iniciativas brasileiras vincula-se em maior ou menor medida ao governo; afinal, é majoritariamente sobre a estrutura estatal e as ações de governo que a sociedade deseja incidir. Para entender melhor como o governo pode abrigar iniciativas de democracia digital de caráter participativo foi realizada a entrevista ${ }^{i}$ que se segue, com Vinicius Wu, 34 anos, Secretário Geral de Governo do Rio Grande do Sul à época. Wu é natural do Rio de Janeiro (RJ) e trabalhou no governo gaúcho entre 2011 e 2014. Inicialmente, foi da Chefia de Gabinete do Governador do Rio Grande do Sul, onde começou o Gabinete Digital, o portal estadual de participação social gaúcho. Em 2013, Wu e o Gabinete Digital seguiram para a Secretaria Geral de Governo do Estado, o que fortaleceu o papel político da plataforma digital de participação. Até $2014 \mathrm{Wu}$ foi o Coordenador Geral do Gabinete Digital e, em 2015, saiu da Coordenação para assumir a Secretaria de Articulação Institucional do Ministério da Cultura.

\section{Como nasceu o Gabinete Digital?}

Iniciamos a concepção com uma prospecção de iniciativas que pudessem fundamentar uma proposta como a que estávamos dispostos a realizar, antes mesmo de assumirmos [o governo estadual gaúcho]. Já em 2009, 2010, o candidato ao governo do estado [Tarso Genro] já buscava alguns elementos para formar uma experiência que proporcionasse a participação da cidadania através de um canal apoiado no uso intensivo das novas tecnologias da 
informação e da comunicação e no uso das novas redes sociais e digitais. Começamos, portanto, um trabalho de diálogo, que transpassou a campanha ao governo do estado em 2010. De alguma maneira, introduzimos na nossa campanha alguns elementos inovadores que buscaram estabelecer algum tipo de diálogo com os eleitores a partir desse uso, digamos, inovador, das novas tecnologias no âmbito da política.

\section{Quem participou na concepção do Gabinete Digital?}

Em 2011, passamos a desenvolver a estrutura nosso Sistema Estadual de Participação Popular e Cidadã ${ }^{1}$, isso era um compromisso de campanha. Constava do nosso programa de governo a ideia de conformar um sistema que contemplasse um conjunto de instrumentos de participação e de interferência da cidadania nas decisões públicas, no âmbito estadual. Sistema esse que, necessariamente, contaria com a dimensão da participação digital, através da internet, além dos inúmeros recursos que já temos disponíveis. Começamos um trabalho de prospecção de iniciativas [de participação digital] de governo em outras partes do mundo (Hamburgo, Islândia, entre outros). Também investigamos iniciativas da sociedade civil e acabamos por adaptar algumas experiências à nossa realidade. Junto a uma equipe enxuta, e com apoio inicial da Fundação Getúlio Vargas, lançamos o Gabinete Digital em maio de 2011. Na realidade, esse percurso não começou em $1^{\circ}$ de janeiro de 2011, pois já vínhamos debatendo a necessidade de buscar a reoxigenação da nossa estrutura democrática e outros temas relacionados aos desafios da democracia contemporânea. Estes são questionamentos que estão na fundamentação do Gabinete Digital.

\footnotetext{
${ }^{1}$ O Sistema Estadual de Participação Popular e Cidadã do Rio Grande do Sul (SEPPC) é composto por instâncias que agem de forma colaborativa, e que elas realizam atividades municipais, regionais e estaduais. Para saber mais sobre o SEPPC acessar <http://www.portaldaparticipacao.rs.gov.br/objetivos-e-principios/>
} 
Sabíamos do desafio que seria conformar um sistema que fosse o mais abrangente possível, como o nosso Sistema Estadual de Participação, que, além da participação digital, conta com a participação presencial e os espaços de representação da sociedade. Sabíamos que era importante a presença de um canal de diálogo com a sociedade ancorado no uso das novas tecnologias de informação e comunicação. Assim que iniciamos a organização do Gabinete Digital.

\section{Quais eram as expectativas iniciais de impacto para dentro do governo?}

A nossa expectativa inicial era de criar um espaço de experimentação, de agregação de canais de interação direta, sem intermediação, entre o poder público e a cidadania. Tínhamos a expectativa também de contribuir para uma mudança de cultura, necessária, e que só pode ser pensada sob uma perspectiva processual. Sem dúvida alguma, o Gabinete Digital já contribuiu para uma mudança na mentalidade e na cultura do serviço público no Estado do Rio Grande do Sul, que ainda é marcada por traços patrimonialistas, pela cultura do sigilo e pelo distanciamento em relação à sociedade. Mais do que isso, sabíamos que era muito importante tentar incluir dentro da dinâmica do poder público executivo estadual a ideia de que é possível recolher da sociedade, em tempo real, através das novas tecnologias, contribuições para a tomada de decisões e para o aperfeiçoamento da gestão pública. E, a partir daí, [o governo] compartilhar decisões com a sociedade. Mesmo longe de ser algo naturalizado pelos gestores ou absorvido plenamente por aqueles que hoje são responsáveis pela construção das políticas públicas do Rio Grande do Sul ou do Brasil, o Gabinete Digital conseguiu dar sua contribuição para uma mudança de mentalidade e cultura. Era necessário ressignificar toda nossa estrutura de participação e mudar também um pouco das 
perspectivas acumuladas historicamente, em especial no Rio Grande do Sul, com o orçamento participativo em Porto Alegre. Portanto, fazia-se necessária uma adequação desses mecanismos de participação de forma que se adaptassem à nova sociedade em rede do século XXI.

\section{Você falou em criar um ambiente de experimentação sem intermediação. A que intermediários você se refere?}

Retomando um pouco a história do Brasil, tivemos um processo de redemocratização, muitas conquistas na Constituição de 88 e, apesar de todos os percalços, um processo de amadurecimento das nossas instituições democráticas - isso foi fruto da mobilização da sociedade brasileira. As nossas estruturas de participação estão inscritas hoje nas estruturas formais do Estado. Os canais de abertura democrática à participação da cidadania, que vão além do voto formal a cada quatro anos, ainda estão muito vinculados à perspectiva de representação que já não encontra o mesmo respaldo que encontrava na sociedade brasileira da década de 1980 e de 1990 . Ou seja, hoje, apesar de suas limitações, o Estado está preparado para receber contribuições e escutar as representações sindicais e as representações que se dão através de conselhos. Afinal, contamos com toda uma estrutura de conselhos municipais, estaduais e federais, e também de conferências, consagradas no imaginário do político nacional. Atualmente, então, o governante não se daria ao luxo de governar sem ouvir as representações sindicais, patronais e sociais - muitas delas originárias do mundo do trabalho. No entanto, há uma precariedade enorme da capacidade do Estado de absorver as novas vozes e novos sujeitos que emergiram na cena pública nacional e que não encontram os canais de abertura, de interferência efetiva, de participação da cidadania, através de estruturas que possam ir além das representações tradicionais. 
Logo, era uma expectativa que tínhamos e uma contribuição que creio estarmos dando: a possibilidade de Estado criar interfaces, interação, diálogo e interlocução com a cidadania para além daqueles mecanismos que mobilizam as estruturas tradicionais de representação, que em grande parte encontram fortes questionamentos de vários setores da sociedade. A crise da representação não atinge somente os partidos políticos e a política tradicional, ela também atinge os sindicatos, as associações e as organizações não governamentais. Estas, tinham um papel muito importante de mobilização e de representação social, por exemplo, nos anos 1990, mas perderam força nos últimos anos. Dessa maneira, o Gabinete Digital é uma experimentação que abre a possibilidade de diálogo entre o Estado e a sociedade tal como a concebemos hoje uma sociedade atomizada, fragmentada, em que cada vez há menos espaço para aquele formato de participação através da representação tradicional do mundo do trabalho.

\section{Você poderia identificar os três principais pontos positivos do Gabinete Digital?}

Primeiro, demos uma contribuição importante para uma necessária mudança de cultura na gestão pública do estado do Rio Grande do Sul. Mudança essa que não se realiza em quatro anos, no curto prazo, mas deve precisa ser internalizada pelas estruturas do Estado e, assim, deve começar a ser feita. O poder público precisa se adaptar à sociedade existente do século XXI, pois nossas estruturas estatais foram conformadas para um tipo de sociedade que eu diria que não existe mais.

Um segundo aspecto que identifico é a mudança de linguagem dentro das estruturas formais de participação e interlocução da cidadania com o Estado; ou seja, há uma mudança de perspectiva na 
forma com que o Estado se reporta à sociedade. Queremos criar uma possibilidade das pessoas se enxergarem no Estado.

Um dos principais pontos positivos é que estamos conformando é o que eu chamaria de um espaço público não estatal, onde a cidadania percebe que o ambiente não é pertencente a um determinado governo, mas à sociedade como um todo.

O Gabinete Digital mostrou-se um canal possível de interlocução com o Estado, que para muitas pessoas é hermético e fechado. Conseguimos criar aberturas e brechas que contribuíram para o aumento da porosidade do Estado. Desta forma, o Gabinete Digital acabou se tornando um mecanismo pelo qual indivíduos que tradicionalmente não participariam de processos de escuta e de diálogo do governo identificavam nessa ferramenta uma abertura efetiva para participação. Conseguimos estabelecer um canal de interlocução num momento em que o governo mais precisou, que foi durante os protestos de 2013, um tipo de mobilização característica do século XXI que se organizou por fora das estruturas de representação, sem tema pré-determinado - não havia locais de fala onde o governo pudesse reunir lideranças e estabelecer um diálogo. O Gabinete Digital talvez tenha sido um dos poucos canais que estabeleceu um ponto de contato entre o Estado e a cidadania mobilizada das ruas. A partir desse espaço, se originaram ações de governo, propostas concretas que procuravam dar atendimento a demandas suscitadas pelas mobilizações.

Acrescentando um último ponto positivo, com a nossa experiência, conseguimos comprovar empiricamente que é possível que os governos adotem as novas tecnologias da informação e comunicação para proporcionar o fortalecimento da cidadania e maior porosidade do estado. Portanto, é sim possível utilizar instrumentos digitais de participação e cidadania na administração pública para alargar, aprofundar e aperfeiçoar a nossa democracia. 
Você citou "ações de governo" - poderia dar um exemplo?

A principal delas foi a instituição, no estado do Rio Grande do Sul, do passe livre estudantil, que não era uma proposta que estava sendo debatida no governo, não constava no nosso horizonte, mas era uma das principais bandeiras apresentadas pelos jovens. A bandeira do passe livre era uma das principais reivindicações que nós identificamos aqui nas mobilizações. O governo absorveu essa demanda, formulou uma proposta, enviou para a Assembleia Legislativa, foi aprovada pela Assembleia, e já está implementada no Rio Grande do Sul.

Queria pedir para você apontar três pontos negativos do Gabinete Digital?

Em primeiro lugar estão a escala e a amplitude referente à participação... a massificação, portanto, por esse mecanismo [o Gabinete Digital]. Podemos hoje nos orgulhar de termos feito, por exemplo, a maior consulta por meio digital que se tem registro no Brasil.

\section{Mas isso não é um ponto negativo...}

Vou explicar... [apesar desse recorde] certamente, não é o universo de participação que gostaríamos e que julgaríamos como ideal. Isto é, ampliar a participação e o conhecimento e apropriação pela cidadania do Gabinete Digital ainda é um desafio. Precisamos aumentar nossa capacidade de comunicação. Outro aspecto, é que a mudança de cultura precisa ser aprofundada. Não conseguimos introduzir alguns elementos indutores que 
inscrevessem na estrutura do Estado mecanismos que cristalizassem a mudança inicialmente.

Por fim, não conseguimos avançar a articulação da experiência do Gabinete Digital a outras estratégias que mobilizassem outros órgãos, no sentido de abertura de dados e do uso de tecnologias livres. Ainda temos algum percurso para que experiências semelhantes possam ser feitas por todos órgãos da administração, que isso possa fluir pelas diversas unidades de governo proporcionando abertura maior e capacidade de diálogo mais intensa entre Estado e sociedade.

Dentro do Gabinete Digital, você poderia falar um pouco sobre a concepção da agenda. Quem decide o que vai ser discutido? Até que ponto o cidadão pode definir qual é a pauta a ser discutida?

No início do Gabinete Digital, tínhamos a ferramenta Governador Responde que procurava responder a essa questão. Por esta ferramenta, a população apresentava mensalmente um tema para que o governador respondesse. Assim, o governador se comprometia a estabelecer um processo de diálogo que pudesse originar respostas efetivas, logo, abria-se a possibilidade de se debater alguma matéria não prevista pelo governo. Por exemplo, um tema que acabou emergindo na sociedade e incidindo sobre o governo foi a organização e estrutura dos bombeiros no estado gaúcho - proposta de emenda à constituição do Estado do Rio Grande do Sul foi levada a diante pelo governador Tarso Genro.

\section{Mas essa ferramenta [Governador Responde] não foi descontinuada?}

Foi descontinuada por vários motivos, entre os quais, a busca que fizemos por outros canais de escuta como o Governo Escuta, pelos 
quais o governo pudesse receber questões da sociedade, de maneira direta, e partir daí estabelecer uma agenda. Outro motivo foi a necessidade de buscar uma participação mais ampliada, pois se num primeiro momento a ferramenta surtiu um efeito muito positivo, depois acabou se inclinando para uma discussão muito vinculada às corporações do Estado, sendo quase que apropriada pelos servidores do governo do Estado que visualizaram [no Governador Responde] a possibilidade de apresentação de suas demandas. As categorias do Estado começaram a se organizar para fazer com que as suas questões fossem as predominantes - por isso ela [a ferramenta] foi descontinuada. Este ano a ferramenta Governador Responde foi retomada com outra formatação: as pessoas podem levantar temas variados desde que inseridos num macro-tema, que em 2014 foi a Copa do Mundo.

\section{Para encerrar, gostaria de fazer mais alguma consideração?}

Temos a consciência de que o Gabinete Digital é o embrião daquilo que se tornará uma prática comum nos governos democráticos do século XXI, que é se apoiar no uso das novas tecnologias, nas possibilidades múltiplas de facilitação da interferência do cidadão nas decisão públicas utilizando as novas tecnologias de informação e comunicação. Contamos com mecanismos e instrumentos que permitem abertura, talvez, inédita, em relação ao acesso à informação, às decisões e ao funcionamento da administração pública. Outro aspecto fundamental, um dos principais pontos de tensão entre Estado e sociedade nas próximas décadas, é a abertura de informações e dados. Para o Gabinete Digital a abertura de informações públicas proporciona o aumento da transparência e do controle social sobre o Estado. Afinal, a redemocratização da democracia passa por uma decodificação do funcionamento da estrutura do Estado. É preciso abrir os códigos do poder; é preciso 
fazer com que as pessoas possam se apropriar efetivamente da dinâmica de funcionamento do Estado, pois somente a partir daí é possível fortalecer os canais de participação da cidadania. Por fim, a aposta que fizemos se mostrou muito adequada aos desafios do tempo presente quando das mobilizações de 2013 - muitas pessoas, inclusive do governo, que tinham dúvidas sobre a pertinência e a utilidade do Gabinete Digital, reconheceram que a escolha que fizemos em 2011 estava correta. Foi uma posta feita pelo próprio governador do estado e, senão fosse esse apoio, não teria sido possível alavancar a iniciativa. Muitas experiências de participação digital esbarram na forma secundária como são tratadas pelo governo, iniciativas muito inovadoras e interessantes não obtêm êxito por não contarem com o suporte que contamos aqui, direto do chefe do executivo. Enfim, 2013 serviu mostrou o acerto dessa aposta e a necessidade de aprofundarmos o uso dessas novas tecnologias para fortalecer e ampliar a democracia.

COMPOLITTICA ASSOCIACCÅ BRASILEIRA DE PESQUISADORES EM COMUNICACAAO E POLIITICA

Presidente: Alessandra Aldé (UERJ)

Vice-Presidente: Luis Felipe Miguel (UnB)

Secretário Executivo: Francisco Jamil Marques (UFC)

Editoras-Chefes:

Alessandra Aldé (UERJ) e Maria Helena Weber (UFRGS)

Editores Executivos:

Edna Miola (UFS), Fernanda Sanglard (UERJ), Rafael

Cardoso Sampaio (UFMG) e Viktor Chagas (UFF)
A Revista Compolítica é uma revista eletrônica da Associação Brasileira de Pesquisadores em Comunicação e Política. Com periodicidade semestral, sua proposta é difundir a produção acadêmica relacionada às interfaces desses campos de estudo.

Ao citar este artigo, utilize a seguinte referência bibliográfica

SVAB, Haydée. Gabinete Digital: uma experimentação que mistura política com novas tecnologias de informação e comunicação (Entrevista com Vinicius Wu). In: Revista Compolítica, n. 4, vol. 2, ed. agosto-dezembro, ano 2014. Rio de Janeiro: Compolítica, 2014. 
